Biochemistry, 2015, 54 (39), pp 6132-6138

DOI: 10.1021/acs.biochem.5b00691

\title{
Biochemical Characterization of a Lanthanide-Dependent DNAzyme with Normal and Phosphorothioate-Modified Substrates
}

\author{
Mahsa Vazin, Po-Jung Jimmy Huang, Żaneta Matuszek and Juewen Liu* \\ Department of Chemistry, Waterloo Institute for Nanotechnology \\ University of Waterloo, Waterloo, Ontario, Canada, N2L 3G1
}

Fax: (+1) 519-746-0435

Phone: (+1) 519-888-4567 extension 38919

E-mail: liujw@uwaterloo.ca

This document is the Accepted Manuscript version of a Published Work that appeared in final form in Biochemistry, copyright (C) American Chemical Society after peer review and technical editing by publisher. To access the final edited and published work see http://dx.doi.org/10.1021/acs.biochem.5b00691 


\begin{abstract}
A trivalent lanthanide $\left(\mathrm{Ln}^{3+}\right)$-dependent RNA-cleaving DNAzyme, Ce13d, was recently isolated via in vitro selection. Ce13d is active in the presence of all $\mathrm{Ln}^{3+}$ ions. By introducing a single phosphorothioate (PS) modification at the cleavage site, its activity with $\mathrm{Ln}^{3+}$ decreases while all thiophilic metals can activate this DNAzyme. This property is unique to Ce13d and is not found in many other tested DNAzymes. This suggests the presence of a well-defined but general metal binding site. Herein, a systematic study of Ce13d with the PO substrate (using $\mathrm{Ce}^{3+}$ ) and the PS substrate (using $\mathrm{Cd}^{2+}$ ) is performed. In both the PO and PS systems, the highest activity was with $\sim 10 \mu \mathrm{M}$ metal ions. Higher concentrations of $\mathrm{Ce}^{3+}$ completely inhibit the activity while $\mathrm{Cd}^{2+}$ only slows the activity down. A comparison of different metal ions suggests that the role of metal is to neutralize the phosphate negative charge. Both systems follow a similar $\mathrm{pH}$-rate profile with a single deprotonation step, indicating similar reaction mechanisms. The activity difference between the $R_{\mathrm{p}}$ and $S_{\mathrm{p}}$ form of the PS substrate is less than 10-fold, which is much smaller than most known RNA-cleaving enzymes. Mutation studies identified eight highly conserved purines, amongst which the two adenines play mainly structural roles while the guanines are likely to involve in metal binding. Ce13d can serve as a model system for further understanding of DNAzyme biochemistry and bioinorganic chemistry.
\end{abstract}


DNAzymes are DNA-based catalysts. ${ }^{1-7}$ Inspired by the chemical functions of ribozymes and the high stability of DNA, DNAzymes were first isolated via in vitro selection in $1994 .{ }^{8}$ Since then, a diverse range of DNAzymes catalyzing various types of chemical reactions have been reported. ${ }^{9}$ Aside from biochemical studies, DNAzymes have quite useful in biosensor development, ${ }^{10-12}$ viral and cancer therapy, ${ }^{1,13}$ and nanotechnology. ${ }^{14}$ Among the different types of DNAzymes, those cleaving RNA have attracted the most attention since they are usually small in size, highly active and can be readily used for the abovementioned applications.

To achieve effective DNAzyme catalysis, metal ions are often required. ${ }^{15}$ For example, $\mathrm{Mg}^{2+}$ is most frequently used because of its physiological abundance and DNAzymes intended for intracellular functions are believed to use $\mathrm{Mg}^{2+} \cdot{ }^{1} \mathrm{~Pb}^{2+}$ and lanthanide ions $\left(\mathrm{Ln}^{3+}\right)$ are used because of their known activity in RNA cleavage. ${ }^{8,16-18} \mathrm{Ln}^{3+}$ are important probes for nucleic acids. ${ }^{19-23}$ They are quite effective in hydrolyzing RNA, ${ }^{24}$ and early examples can be traced back to the cleavage of tRNA. ${ }^{25} \mathrm{Ln}^{3+}$ inhibit the hammerhead ribozyme and the 8-17 DNAzyme, ${ }^{22,26}$ but accelerate the leadzyme and a $\mathrm{Mg}^{2+}$-dependent ligase. ${ }^{33,34} \mathrm{Ln}^{3+}$ were also used to select DNAcleaving DNAzymes together with $\mathrm{Zn}^{2+} .{ }^{27} \mathrm{~A} \mathrm{~Pb}^{2+}$-dependent DNAzyme (GR5) was found to have moderate activity with a few heavy $\mathrm{Ln}^{3+}$ (the highest rate is $\sim 0.02 \mathrm{~min}^{-1}$ ). ${ }^{28}$ We recently isolated a few trivalent lanthanide-dependent RNA-cleaving DNAzymes. ${ }^{16-18}$

One of those $\mathrm{Ln}^{3+}$-dependent DNAzymes (named Ce13d) is very interesting and deserves more careful studies. First, it works with all $\mathrm{Ln}^{3+}$ with a similar activity, ${ }^{16}$ suggesting that it has a general $\mathrm{Ln}^{3+}$ binding site. Second, with a single phosphorothioate (PS) modification, it becomes active with all thiophilic metal ions (e.g. $\mathrm{Cu}^{2+}, \mathrm{Hg}^{2+}, \mathrm{Cd}^{2+}$ and $\mathrm{Pb}^{2+}$ ), while its activity drops significantly with $\mathrm{Ln}^{3+} \cdot{ }^{29}$ Such a broad spectrum of metal activity is not observed with other tested DNAzymes such as the well-known 17E DNAzyme, the uranyl-dependent DNAzyme, or GR5. ${ }^{29}$ None of these 
DNAzymes work with $\mathrm{Cd}^{2+}$ even with the incorporation of the PS-modified substrate. ${ }^{29}$ In this work, we perform a careful biochemical characterization on Ce13d. In particular, the normal phosphate and the PS-modified substrates are compared using the same enzyme but with different metals. New insights are gained by the side-by-side comparison to explore the effect of metal concentration, $\mathrm{pH}$ and mutations.

\section{Materials and Methods}

Chemicals. All the DNA samples were from Eurofins (Huntsville, AL). The metal salts were from Sigma-Aldrich. The sequences and modifications of the DNA samples are listed in Table S1 of Supporting Information. The buffers were from Mandel Scientific (Guelph, Ontario, Canada). Milli-Q water was used for making all the solutions and buffers.

pH-dependent studies. The DNAzyme complex was formed by annealing $5 \mu \mathrm{M}$ FAM-labeled substrate (PO or PS) and $7.5 \mu \mathrm{M}$ of the enzyme in water with $175 \mathrm{mM} \mathrm{NaCl}$ by warming up the sample to $80{ }^{\circ} \mathrm{C}$ for $1 \mathrm{~min}$ following slow cooling down to room temperature. Then, the sample was diluted 5 times into $50 \mathrm{mM}$ of the various buffers. A final concentration of $10 \mu \mathrm{M}$ metal ions was incubated with $35 \mu \mathrm{L}$ of $1 \mu \mathrm{M}$ DNAzyme complex in acetate (pH 4.2-5.6), MES (pH 5.8-6.8) or MOPS (pH 7.0-7.2) buffer. At designated time points, an aliquot was transferred to the gel loading buffer (11 mM EDTA, $8 \mathrm{M}$ urea with bromophenol blue) to quench the reaction. The samples were analyzed by $15 \%$ dPAGE (120 V for $90 \mathrm{~min})$. Gel images were documented with a Bio-Rad ChemiDoc MP imaging system. Kinetics studies in the presence of various metal concentrations or of the mutated DNAzymes were carried out in a similar way. The default buffer condition is buffer $\mathrm{A}(25 \mathrm{mM} \mathrm{NaCl}, 50 \mathrm{mM}$ MES, $\mathrm{pH}$ 6.0). Other kinetic assays were performed 
in a similar way but by changing the metal ion species or concentration. Most biochemical assays were run in triplicate and the standard deviations are plotted as error bars.

Enzyme concentration effect. For studying the effect of DNAzyme concentration (with the PO substrate), the $1 \mu \mathrm{M}$ DNAzyme complex was formed as described above, and the $0.1 \mu \mathrm{M}$ sample was prepared by diluting the $1 \mu \mathrm{M}$ sample by 10 -fold. The $10 \mu \mathrm{M}$ sample was prepared using the same $1 \mu \mathrm{M}$ substrate strand but with a final concentration of $10 \mu \mathrm{M}$ enzyme strand. These DNAzyme complexes were finally dissolved in buffer A and the reaction was stopped at $10 \mathrm{~min}$ after adding $\mathrm{Ce}^{3+}$.
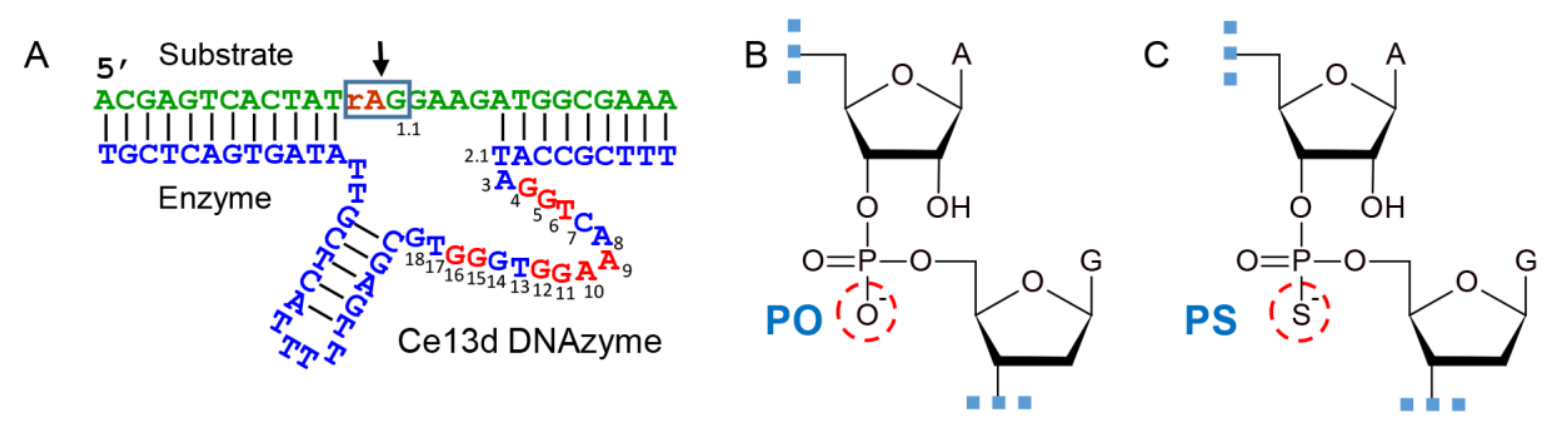

Figure 1. (A) The secondary structure of the Ce13d DNAzyme. The substrate strand is in green, and the cleavage junction rAG is shown in the box. The enzyme strand is in blue/red and the red nucleotides are highly important for catalysis. The structure of the rAG cleavage junction with (B) the normal phosphate (PO) linkage and (C) the phosphorothioate (PS) linkage.

\section{Results and Discussion}

Metal-dependent activity. The structure of the Ce13d DNAzyme is shown in Figure 1A, containing a substrate and an enzyme strand. The cleavage junction of the substrate is indicated by the arrowhead. This cleavage junction can be either a normal phosphate (PO, Figure 1B) or a 
modified phosphorothioate (PS, Figure 1C). To gain a quantitative understanding, we first measured its rate using the normal PO substrate and $10 \mu \mathrm{M}$ of various metal ions. $\mathrm{Ce}^{3+}$ gave a rate of $0.18 \pm 0.02 \mathrm{~min}^{-1}, \mathrm{~Pb}^{2+}$ was nearly 20 -fold slower, while $\mathrm{Cd}^{2+}$ and $\mathrm{Cu}^{2+}$ were inactive (Figure $2 \mathrm{~A})$. With the PS substrate, $\mathrm{Pb}^{2+}\left(0.11 \pm 0.02 \mathrm{~min}^{-1}\right), \mathrm{Cd}^{2+}\left(0.06 \pm 0.01 \mathrm{~min}^{-1}\right)$, and $\mathrm{Cu}^{2+}(0.021 \pm$ $0.003 \mathrm{~min}^{-1}$ ) became more efficient, while $\mathrm{Ce}^{3+}$ became slower. Therefore, with the PS modification, the rate in presence of $\mathrm{Ce}^{3+}$ dropped by $\sim 11$-fold compared to that with the PO substrate. The other metals were faster with the PS substrate: $\mathrm{Pb}^{2+}$ by 11 -fold, $\mathrm{Cu}^{2+}$ by 172 -fold and $\mathrm{Cd}^{2+}$ by 196 -fold. This assay agrees with the soft-hard acid-base theory, where $\mathrm{Ce}^{3+}$ has a stronger affinity with oxygen, $\mathrm{Cd}^{2+}$ and $\mathrm{Cu}^{2+}$ bind sulfur ligands better, and $\mathrm{Pb}^{2+}$ can bind both. ${ }^{30}$ Therefore, using PS-modified substrate is a good way to obtain DNAzymes active with thiophilic metals,${ }^{31}$ which is consistent with the ribozyme literature. ${ }^{32,33}$

Next, $\mathrm{Ce}^{3+}$ and $\mathrm{Cd}^{2+}$ were used to study the PO and PS systems, respectively. We first measured activity at various $\mathrm{Ce}^{3+}$ concentrations (Figure $2 \mathrm{~B}$ ). Without $\mathrm{Ce}^{3+}$, no cleavage was observed in 2 $\mathrm{h}$ (black dots). At low $\mathrm{Ce}^{3+}$ concentrations, both the cleavage rate and the final cleavage yield increased with an increase in $\mathrm{Ce}^{3+}$ concentration. The cleavage activity peaked at $10 \mu \mathrm{M} \mathrm{Ce}^{3+}$, where the final cleavage reached $\sim 80 \%$. All the data can fit into a first-order reaction kinetics and the rate constants are plotted in Figure 2C. At even higher metal concentrations (e.g. $50 \mu \mathrm{M}$ or higher), however, the final cleavage yield dropped. With $50 \mu \mathrm{M} \mathrm{Ce}^{3+}$, only $40 \%$ cleavage was achieved; with $100 \mu \mathrm{M} \mathrm{Ce}^{3+}$, the final cleavage was below $20 \%$. For these two samples, cleavage only occurred in the first two minutes, after which the enzyme was completely inhibited. 

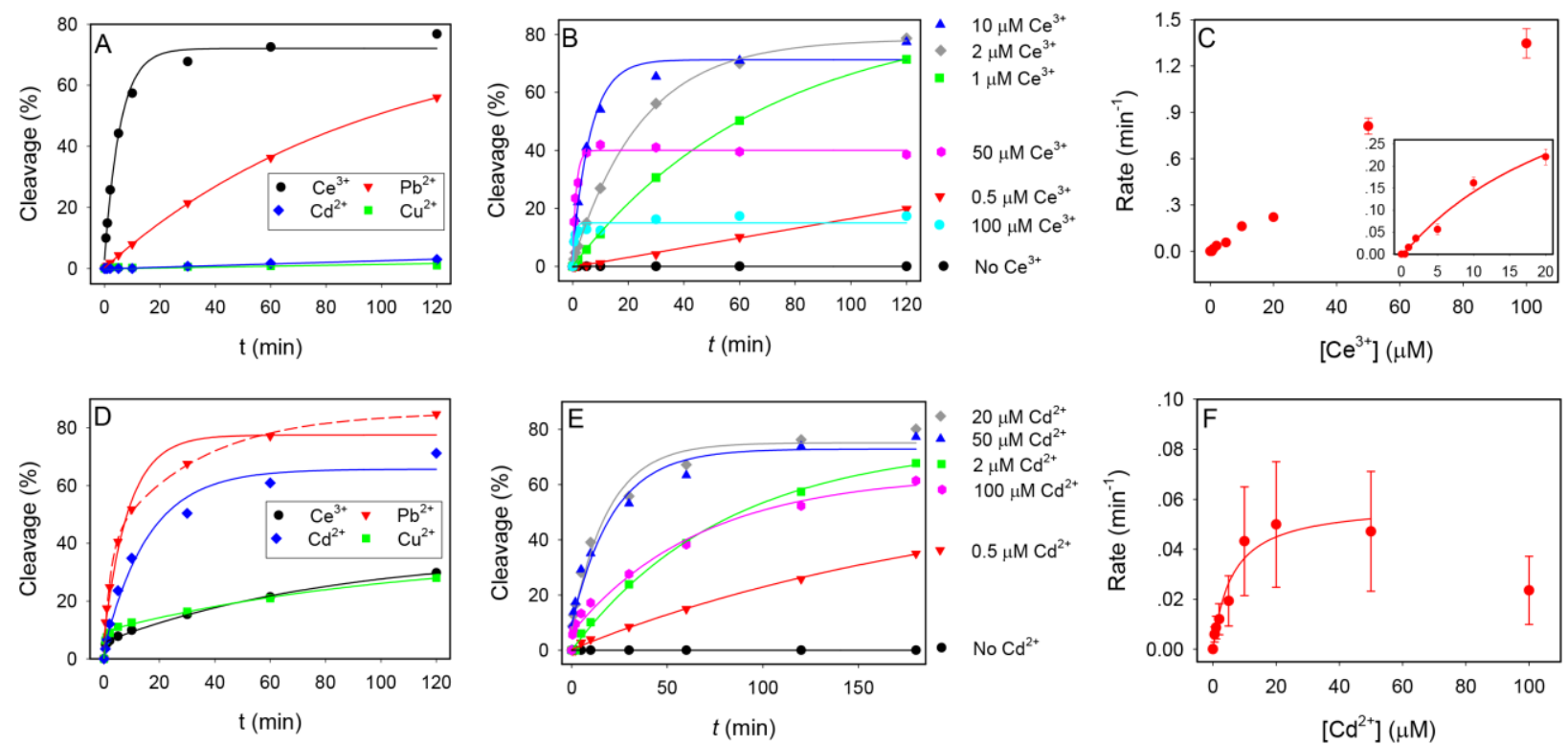

Figure 2. Kinetics of Ce13d cleavage (A) the PO substrate or (D) the PS substrate in the presence of various metal ions $(10 \mu \mathrm{M})$. The dashed red line in (D) is fitted to a double exponential kinetics and the rest are single exponential. Kinetics of Ce13d cleavage with various concentrations of (B) $\mathrm{Ce}^{3+}$ for the PO substrate or $(\mathrm{E}) \mathrm{Cd}^{2+}$ for the PS substrate. Rate constant of cleavage as a function of (C) $\mathrm{Ce}^{3+}$ for the PO substrate or $(\mathrm{F}) \mathrm{Cd}^{2+}$ for the PS substrate. Note that the PS substrate data are from a mixture of $R_{\mathrm{p}}$ and $S_{\mathrm{p}}$ diastereomers and the obtained rate constants are averaged values.

Due to the low final cleavage yield at high $\mathrm{Ce}^{3+}$ concentrations, the rate obtained from the fitting still went up (Figure 2C). To avoid this artifact, we did not include the last two data points in our binding curve and the apparent dissociation constant $\left(K_{\mathrm{d}}\right)$ was determined to be $27.5 \pm 18 \mu \mathrm{M} \mathrm{Ce}^{3+}$ for binding a single metal ion (inset of Figure 2C), which is comparable to the value obtained from the $\mathrm{Tb}^{3+}$ luminescence study. ${ }^{34}$

This result suggests two competing processes at high $\mathrm{Ce}^{3+}$ concentrations: the DNAzyme can be either activated or inhibited by lanthanide ions. This is not surprising since $\mathrm{Ln}^{3+}$ are trivalent 
cations with strong affinity to the DNA phosphate and base. A high concentration of $\operatorname{Ln}^{3+}$ may disrupt nucleic acid secondary structures. ${ }^{35}$ Our final DNAzyme concentration is $0.7 \mu \mathrm{M}$ for the above assays, and there are 78 phosphates in each DNAzyme complex, leading to a total phosphate concentration of $55 \mu \mathrm{M}$. Since strong inhibition occurred with $50 \mu \mathrm{M} \mathrm{Ce}^{3+}$, we suspect that when the ratio between phosphate and $\mathrm{Ln}^{3+}$ is $\sim 1: 1, \mathrm{Ln}^{3+}$ start to disrupt the DNA structure. If this hypothesis is true, we should be able to delay the inhibition effect by using a higher DNA concentration. To test this, we fixed the substrate concentration and increased the enzyme strand concentration by 10 -fold. Indeed, only moderate inhibition was observed with $100 \mu \mathrm{M} \mathrm{Ce}^{3+}$ (green dots, Figure 3). On the other hand, if both the substrate and enzyme strand were decreased to 0.1 $\mu \mathrm{M}$, inhibition occurred at even lower $\mathrm{Ce}^{3+}$ concentrations (black dots).

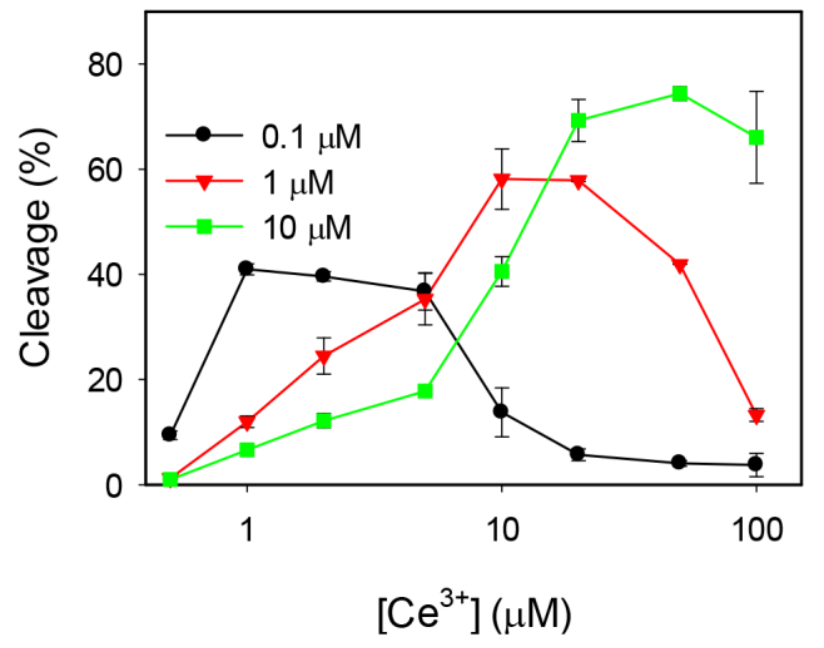

Figure 3. Percentage of the $\mathrm{PO}$ substrate cleavage by $\mathrm{Ce} 13 \mathrm{~d}$ in the presence of various concentrations of $\mathrm{Ce}^{3+}$ after $1 \mathrm{~h}$. The DNAzyme concentration was $0.1 \mu \mathrm{M}$ (substrate and enzyme), $1 \mu \mathrm{M}$ (substrate and enzyme), or $1 \mu \mathrm{M}$ substrate with $10 \mu \mathrm{M}$ enzyme strand (green squares). The inhibition effect can be delayed by adding more DNA. 
PS-modified substrate. Next, we varied the $\mathrm{Cd}^{2+}$ concentration for cleaving the PS-modified substrate (Figure 2E). A similar trend was observed, and inhibition occurred with over $50 \mu \mathrm{M} \mathrm{Cd}^{2+}$. The $\mathrm{Cd}^{2+}$-induced inhibition, however, is quite different from the $\mathrm{Ce}^{3+}$ inhibition. Even with 100 $\mu \mathrm{M} \mathrm{Cd}{ }^{2+}$, time-dependent cleavage was still observed after $3 \mathrm{~h}$, while with $100 \mu \mathrm{M} \mathrm{Ce}^{3+}$, the DNAzyme was completely inactive after $2 \mathrm{~min}$. Therefore, inhibition of the DNAzyme by $\mathrm{Cd}^{2+}$ is milder. Unlike a complete disruption of DNAzyme structure by $\mathrm{Ce}^{3+}, \mathrm{Cd}^{2+}$ might only cause reversible changes in the DNAzyme. The $K_{\mathrm{d}}$ was calculated to be $6.0 \pm 2.8 \mu \mathrm{M}$ for $\mathrm{Cd}^{2+}$ using the PS substrate.

$\boldsymbol{R}_{\mathrm{p}}$ and $S_{\mathrm{p}}$ diastereomers. A PS modification results in two diastereomers: $R_{\mathrm{p}}$ and $S_{\mathrm{p}}{ }^{36}$ The above assays used a mixture of the two, and the rates obtained are averaged values. In fact, the single exponential fittings in Figure 2D do not follow all the data points, and the system fits better using a bi-exponential equation. To gain further insights, we isolated each diastereomer by HPLC and then tested with the two metals. The separation and chiral assignment were described in another paper. ${ }^{31}$ With $\mathrm{Ce}^{3+}$ (Figure 4A), the PO substrate is cleaved $\left(0.18 \pm 0.02 \mathrm{~min}^{-1}\right) 15$ times faster than the $S_{\mathrm{p}}\left(0.012 \pm 0.001 \mathrm{~min}^{-1}\right)$, while the $S_{\mathrm{p}}$ substrate is cleaved 8 times faster than the $R_{\mathrm{p}}(0.0016 \pm$ $\left.0.0002 \mathrm{~min}^{-1}\right)$. Since $\mathrm{Ce}^{3+}$ is a hard metal that likes oxygen based ligands, it is likely that the pro$R_{\mathrm{p}}$ oxygen is responsible for binding to $\mathrm{Ce}^{3+}$. The assay with $\mathrm{Cd}^{2+}$ was further performed (Figure 4B), yielding a $R_{\mathrm{p}}$ rate of $0.12 \pm 0.02 \mathrm{~min}^{-1}$, which is quite similar to that of the $\mathrm{PO}$ with $\mathrm{Ce}^{3+}$. Therefore, the activity can be nearly fully rescued by $\mathrm{Cd}^{2+}$. On the other hand, the $\mathrm{Cd}^{2+} / S_{\mathrm{p}}$ rate is slightly slower $\left(0.028 \mathrm{~min}^{-1}\right)$, while the PO substrate is essentially inactive with $\mathrm{Cd}^{2+}$.

Most known RNA-cleaving enzymes (e.g. the hammerhead ribozyme, ${ }^{32} \mathrm{HDV}$ ribozyme, ${ }^{33}$ 10-23 DNAzyme,${ }^{37}$ RNase $\mathrm{P},{ }^{38}$ Group II intron, ${ }^{39}$ ) use pro- $R_{\mathrm{p}}$ for metal binding $\left(\right.$ mostly $\mathrm{Mg}^{2+}$ ). This study also indicates that the pro- $R_{\mathrm{p}}$ oxygen is more important for metal binding in the Ce13d DNAzyme. 
The difference in the rate for the $R_{\mathrm{p}}$ and $S_{\mathrm{p}}$ substrates is quite small (8-fold with $\mathrm{Ce}^{3+}$ and 4-fold with $\mathrm{Cd}^{2+}$ ), suggesting that even the pro- $S_{\mathrm{p}}$ oxygen atoms might contribute to metal binding. For comparison, the hammerhead ribozyme $S_{\mathrm{p}}$ is $>100$ times faster than $R_{\mathrm{p}}$ in presence of $\mathrm{Mg}^{2+} .32,40$

Broadly speaking, the role of metal in RNA cleavage is related to activation of the $2^{\prime}-\mathrm{OH}$ nucleophile by assisting its deprotonation, or neutralizing the negative charge on the phosphate at the transition state of the reaction. ${ }^{41}$ For the Ce13d DNAzyme, all the trivalent lanthanide ions (with PO substrate), and $\mathrm{Cd}^{2+}, \mathrm{Cu}^{2+}$, and $\mathrm{Pb}^{2+}$ (with PS substrate) have a similar activity (e.g. ranging from 0.02 to $0.18 \mathrm{~min}^{-1}$ with $10 \mu \mathrm{M}$ metal ions). These data allow us to carry out an initial analysis. To activate $2^{\prime}-\mathrm{OH}$, the metal ion acts as a general base, and the $\mathrm{p} K_{\mathrm{a}}$ values of metal bound water need to be compared. For example, the $\mathrm{p} K_{\mathrm{a}}$ for $\mathrm{Pb}^{2+}$ is 7.2 and for $\mathrm{Cd}^{2+}$ is $10.1 .^{42,43}$ This $\sim 3$ decade $\mathrm{p} K_{\mathrm{a}}$ difference results in only $\sim 1$-fold difference in rate of the PS substrate. For the PO substrate, the $\mathrm{p} K_{\mathrm{a}}$ of $\mathrm{Ce}^{3+}$ is 9.3 , which is between those of $\mathrm{Pb}^{2+}$ and $\mathrm{Cd}^{2+}$, yet $\mathrm{Ce}^{3+}$ has the fastest rate. Therefore, the $\mathrm{p} K_{\mathrm{a}}$ of metal bound water does not correlate with the observed activity, and the role of metal is thus unlikely for direct activation of the $2^{\prime}-\mathrm{OH}$. This is quite different from the case of the 17E DNAzyme, where a nice correlation can be observed between the metal $\mathrm{p} K_{\mathrm{a}}$ and activity. ${ }^{42,44}$

The switching of metal preference by the PS modification directly points at the importance of metal binding to phosphate. Compared to most divalent metal ions, which bind to nucleotide acids with $\mathrm{mM}$ affinity (e.g. using $\mathrm{pUpU}$ as a model), ${ }^{30}$ lanthanide binding yields $\mu \mathrm{M}$ affinity. ${ }^{45}$ This is probably a primary reason that lanthanides are generally more active for Ce13. It needs to be noted that the +3 charge alone is insufficient, since Ce13d cannot be activated by $\mathrm{Sc}^{3+} \cdot{ }^{16}$ In addition to the phosphate coordination, the metal must also bind to other sites in the DNAzyme, and the binding pocket is sensitive to the metal size as well. When the PS modification is introduced, 
binding to thiophilic metal ions is enhanced. For example, the log of binding constant of $p U p(s) U$ to $\mathrm{Cd}^{2+}$ increases $\sim 0.7$ unit compared to that of $\mathrm{pUpU}{ }^{46}$ Taken together, the metals are likely to play a role to neutralize the phosphate charge.
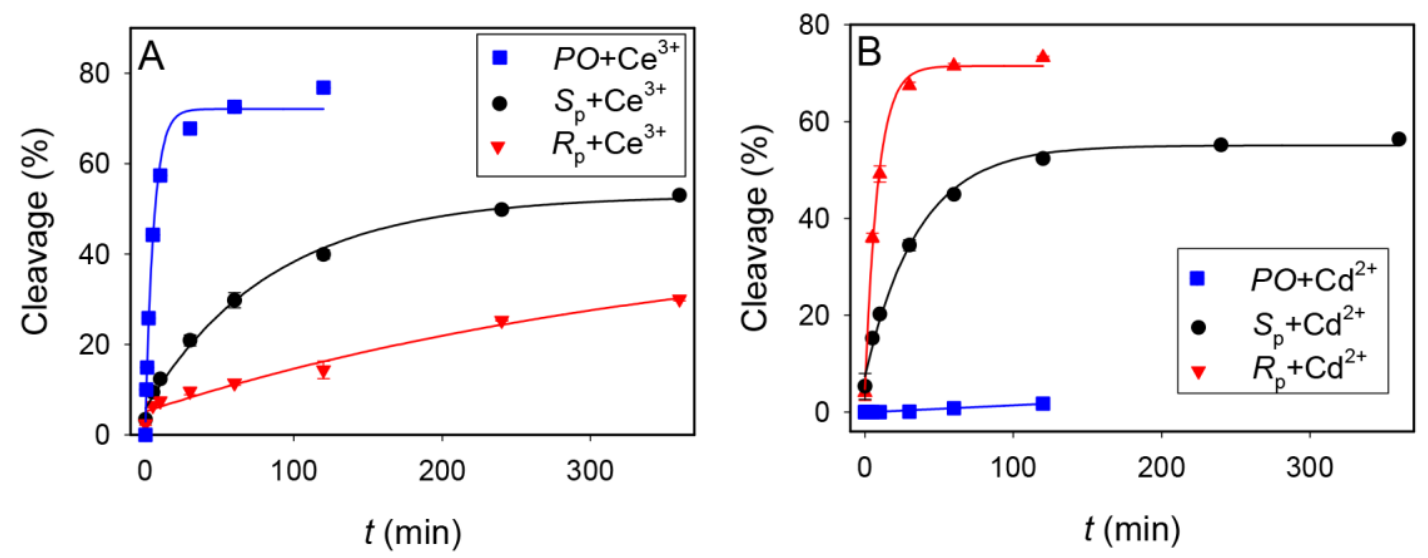

Figure 4. Cleavage kinetics of the three types of substrates (PO, $R_{\mathrm{p}}$ and $S_{\mathrm{p}}$ ) by the Ce13d DNAzyme in the presence of $10 \mu \mathrm{M} \mathrm{Ce}^{3+}(\mathrm{A})$ or $\mathrm{Cd}^{2+}(\mathrm{B})$.

Effect of pH. To gain further insights into the mechanism of Ce13d catalysis, we studied the enzyme activity as a function of $\mathrm{pH}$ first using the PO substrate and $\mathrm{Ce}^{3+}$. In Figure $5 \mathrm{~A}$, the $\log$ of the cleavage rate as a function of $\mathrm{pH}$ is plotted. In general, the rate is faster at higher $\mathrm{pH}$ from $\mathrm{pH}$ 4.8 to 7. At even higher $\mathrm{pH}$, the kinetics are complicated and cannot fit to a single rate. Therefore, we focus our discussion in the slightly acidic region. After $\mathrm{pH} 6$, the rate increase slowed down. In the $\mathrm{pH} 4.8$ to 5.8 region, a linear relationship is obtained with a slope of $1.02 \pm 0.12$ (close to 1.0, Figure 5B), suggesting a single deprotonation step in the reaction process. This is a typical $\mathrm{pH}$ response for RNA-cleaving DNAzymes. ${ }^{44}$ As explained in the previous section, this deprotonation is unlikely to be related to the metal ion directly. 
A similar observation was made with the PS substrate in the presence of $\mathrm{Cd}^{2+}$ (Figure 5C). The slope in the $\mathrm{pH}$ region from 4.8 to 5.8 is $1.04 \pm 0.15$ (Figure 5D), also indicating a single deprotonation step. At each $\mathrm{pH}$, the rate of this system is slightly slower than the normal $\mathrm{PO} / \mathrm{Ce}^{3+}$ system, but the trend of the rate change is comparable. From the $\mathrm{pH}$ probing standpoint, our results suggest that the mechanism of these two systems might be the same. The coordination environment of the metal is likely to be largely maintained in spite of the PO/PS switching. The only difference is that the metal ion is changed from $\mathrm{Ce}^{3+}$ to $\mathrm{Cd}^{2+}$ due to the PS modification, and the $\mathrm{pH}$ titration does not probe this metal binding to the phosphate.
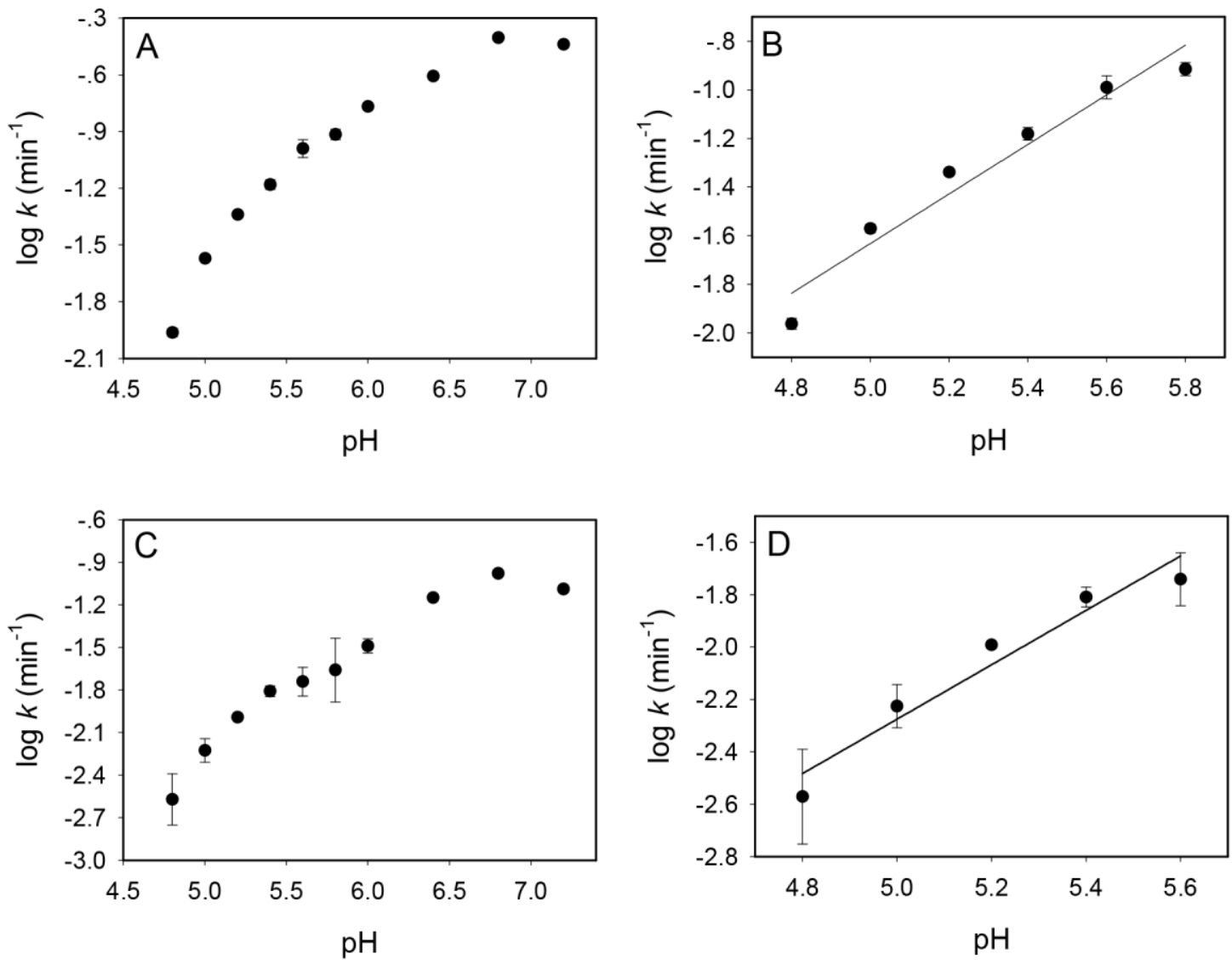
Figure 5. pH-dependent activity of the Ce13d DNAzyme with (A) $\mathrm{Ce}^{3+}$ for the PO substrate or (C) $\mathrm{Cd}^{2+}$ for the PS substrate. Fitting of the data in the $\mathrm{pH}$ region from 4.8 to 5.8 for (B) $\mathrm{Ce}^{3+}$ for the PO substrate or (D) $\mathrm{Cd}^{2+}$ for the PS substrate.

Enzyme mutation studies. The Ce13d DNAzyme has a bulged hairpin structure, and our preliminary studies indicated that the hairpin plays only a structural role and catalytically important nucleotides reside in the bulged loop. ${ }^{16}$ To identify the important nucleotides and their roles in catalysis, we next performed a systematic mutation study. Mutation of conserved nucleotides often abolishes catalysis, thus giving us clues about the mechanism of DNAzyme action. Such mutation studies may also help us to identify novel DNAzyme variants with better activity.

First, the DNAzyme loop region was studied. The numbering of the nucleotides in the loop is shown in Figure 1A. We systematically mutated a total of 16 nucleotides, from $A_{3}$ to $G_{18}$. Each nucleotide was changed to the rest three (e.g. A to C, G and T), giving a total of 48 mutants. We first observed that the activity pattern for these mutants are very similar between the PO substrate with $\mathrm{Ce}^{3+}$ (Figure 6A) and the PS with $\mathrm{Cd}^{2+}$ (Figure 6B), suggesting that the nucleotides in the loop are playing a similar role in both cases. $A_{3}$ is relatively well tolerated to all the applied mutations, suggesting that this position does not serve an important functional purpose. On the other hand, eight purines $\left(\mathrm{G}_{4}, \mathrm{G}_{5}, \mathrm{~A}_{9}, \mathrm{~A}_{10}, \mathrm{G}_{11}, \mathrm{G}_{12}, \mathrm{G}_{15}\right.$ and $\mathrm{G}_{16}$ ) are highly conserved (marked red in Figure 1A). Mutating any of them to any other nucleotides abolishes the enzyme activity. On the other hand, mutations in other nucleotides such as $\mathrm{C}_{7}, \mathrm{~T}_{13}$, and $\mathrm{G}_{14}$ do not completely disturb the enzyme activity; they are probably more important for the stabilization of the enzyme structure. Another observation is that some nucleotides can tolerate purine-to-purine or pyrimidine-topyrimidine mutations but not otherwise, for example, $\mathrm{C}_{7} \mathrm{~T}, \mathrm{~T}_{13} \mathrm{C}$, and $\mathrm{T}_{17} \mathrm{C}$. Overall, the current 
enzyme appears to be an optimal sequence, and most of the mutations decreased the enzyme activity.
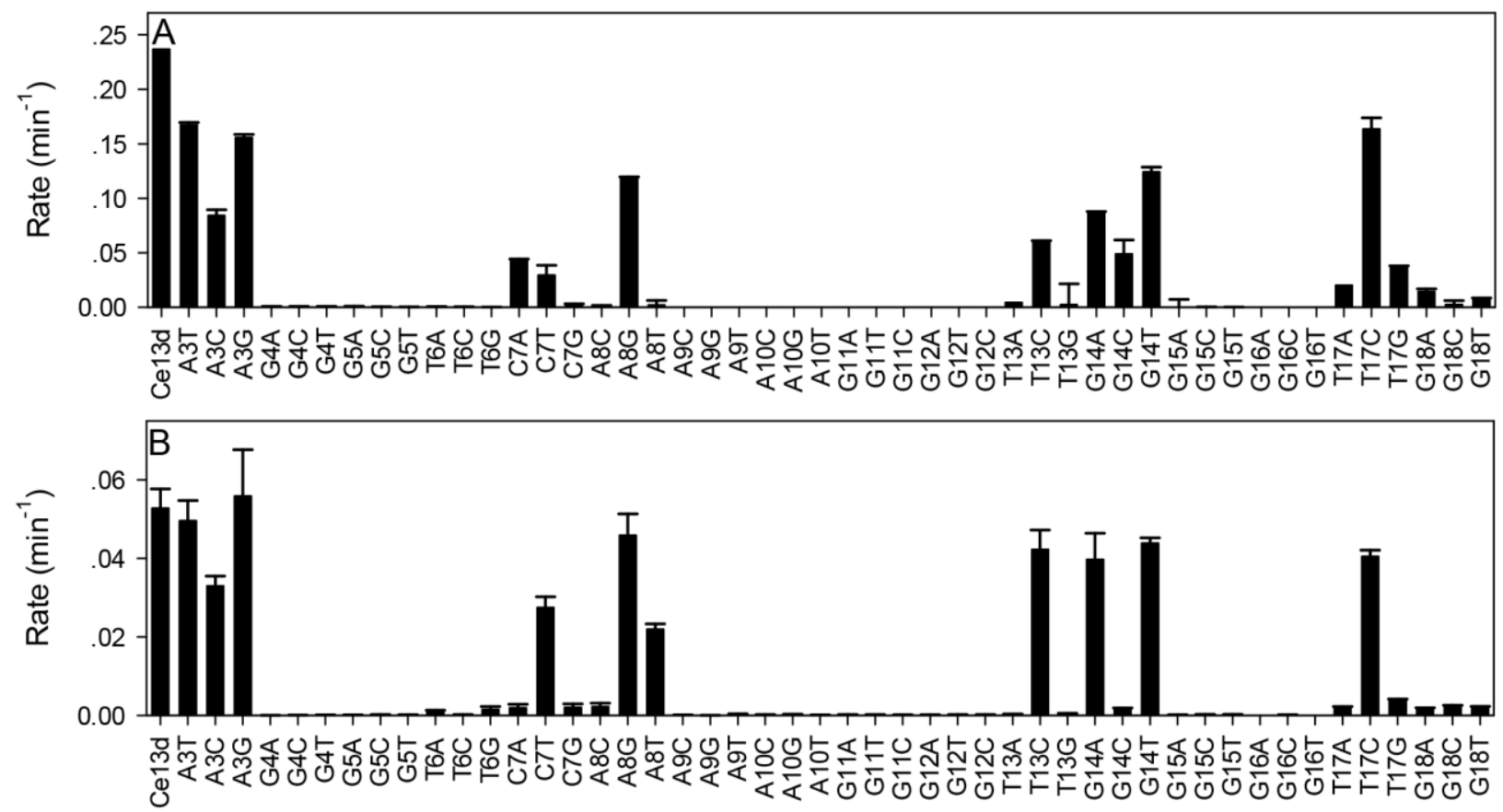

Figure 6. Activity of Ce13d mutants with (A) the PO substrate in the presence of $10 \mu \mathrm{M} \mathrm{Ce}{ }^{3+}$ and (B) the PS substrate in the presence of $10 \mu \mathrm{M} \mathrm{Cd}^{2+}$.

Conserved purine to hypoxanthine (HX) mutations. Out of these eight conserved purines, there are three pairs of guanine dimers $\left(\mathrm{G}_{4} \mathrm{G}_{5}, \mathrm{G}_{11} \mathrm{G}_{12}\right.$, and $\left.\mathrm{G}_{15} \mathrm{G}_{16}\right)$. In addition, two unpaired guanines are present near the cleavage junction in the substrate. These four pairs may form a G-quadruplex structure, which is observed in a number of aptamers but not yet reported in RNA-cleaving DNAzymes. ${ }^{47}$ To test this, we further mutated each guanine to HX. The structures of A, G and HX are shown in Figure 7A. HX can be considered to be an intermediate molecule between A and G. 
Compared to G, HX misses the 2-amine group, while compared to A, the 6-amino group in A is mutated to an oxo group.

Mutations to $\mathrm{HX}$ from $\mathrm{G}_{4}, \mathrm{G}_{5}, \mathrm{G}_{11}$ and $\mathrm{G}_{15}$ only slightly decreased the activity (less than 5-fold), while $\mathrm{G}_{16}$ or $\mathrm{G}_{12}$ to $\mathrm{HX}$ almost had no effect (Figure $7 \mathrm{~B}$ ). These results indicate that the 2-amino groups in these guanines are not involved in important structural or functional roles. The fact that all the important guanines can be mutated to HX rules out the possibility of G-quadruplex, since in a G-quadruplex, the 2-amino group is critical to maintain the hydrogen bonding network and HX cannot support it. Most of the above discussions are focused on metal binding, and we cannot rule out base mutation induced changes in hydrogen bonding patterns in the DNAzyme and the related tertiary structure changes ${ }^{48}$ The resolution of biochemical assays cannot probe such effects and more accurate spectroscopic methods are needed to fully understand it.
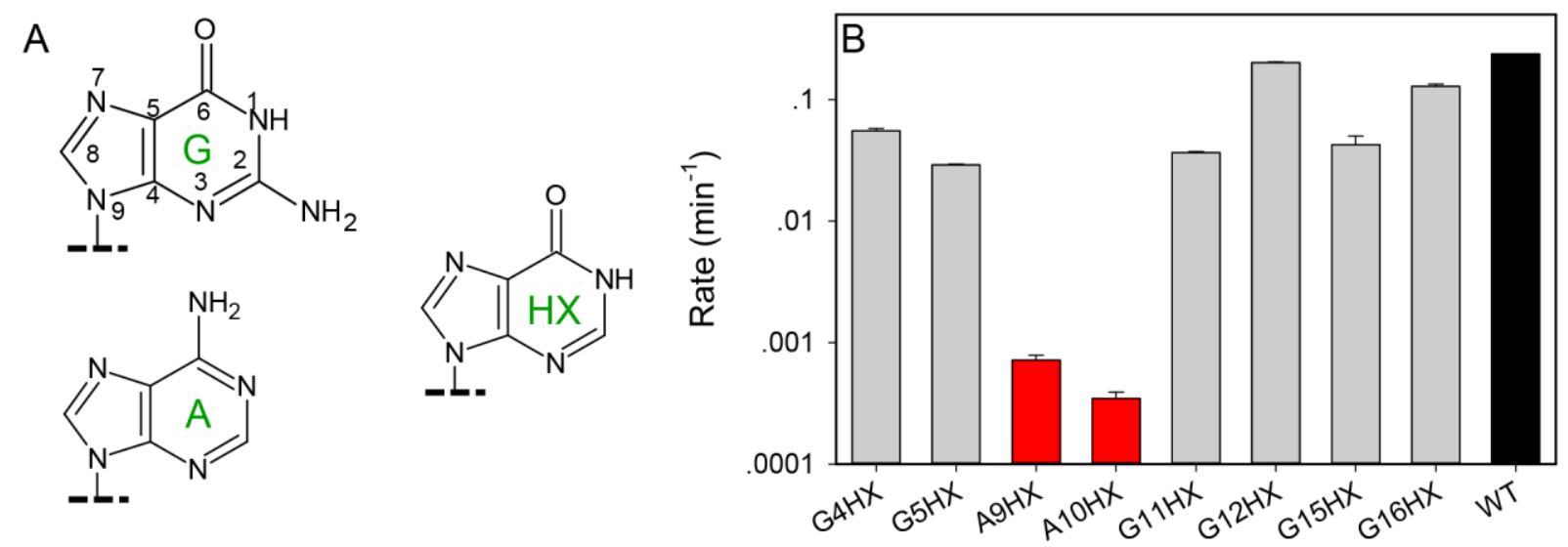

Figure 7. (A) Structures of adenine, guanine and hypoxanthine (HX). Note that the amino group in $\mathrm{G}$ is required for quadruplex formation. (B) Activity of HX-substituted Ce13d mutants plotted on the log scale. All these nucleotides are highly conserved based on the previous round of mutational studies. The rate for cleavage of the PO substrate in the presence of $10 \mu \mathrm{M} \mathrm{Ce}^{3+}$ is 
shown. WT denotes for the wild-type DNAzyme. The two adenine mutations are marked in red and their activity dropped by more than 100-fold compared to the WT.

To gain further insights, we also mutated the two conserved adenines to HX. Interestingly, both mutations abolished the activity. This is in sharp contrast to the above guanine mutations. The 6amino group in adenine is not a good metal ligand since its free electron pair is shared with the conjugated ring. On the other hand, the 6-oxo group in HX is a better metal ligand. Therefore, the abolished activity for these two substitutions is unlikely to be related to the loss of metal coordination. The 6-amino group in adenine is a hydrogen bond donor while the 6-oxo in HX is hydrogen bond acceptor. Therefore, these two adenines might be critical in hydrogen bonding and they play a structural role.

\section{Conclusions}

In summary, we performed a careful biochemical study on a new lanthanide-dependent DNAzyme, Ce13d. Ce13d is the only known DNAzyme that works with all the lanthanides with the normal PO substrate, but with all soft metals with the PS substrate. The PS-modified substrate indicates a relatively weak thio effect for both the $R_{\mathrm{p}}$ and $S_{\mathrm{p}}$ form, while metal binding is likely via the pro- $R_{\mathrm{p}}$ oxygen in the original substrate. We concluded that the metal is mainly responsible for neutralizing the phosphate charge instead of activating the $2^{\prime}-\mathrm{OH}$. Both the PS and PO substrate cleave by the same mechanism as indicated by their similar $\mathrm{pH}$ profiles, where a single deprotonation step is involved. For metal concentration dependent studies, both $\mathrm{Ce}^{3+}$ and $\mathrm{Cd}^{2+}$ inhibit their corresponding DNAzyme complex at high concentrations. However, $\mathrm{Ce}^{3+}$ inhibition is stronger and takes place more quickly. The mutation studies have identified eight highly conserved purines, 
where the two adenines are believed to play mainly structural roles, while the six guanines might involve in metal binding. The presence of a guanine rich metal binding pocket is a special feature of this DNAzyme.

\section{Funding}

Funding for this work is from the Natural Sciences and Engineering Research Council of Canada (NSERC); Grant number: 386326.

\section{Supporting Information}

The Supporting Information is available free of charge on the ACS Publications website at DOI: 10.1021/acs.bio-chem.5b00691.

A table with DNA sequences used in this work. (PDF) 


\section{References}

1. Santoro, S. W., and Joyce, G. F. (1997) A general purpose RNA-cleaving DNA enzyme, Proc. Natl. Acad. Sci. U.S.A. 94, 4262-4266.

2. $\quad$ Breaker, R. R. (1997) DNA enzymes, Nat. Biotechnol. 15, 427-431.

3. Lu, Y. (2002) New transition metal-dependent dnazymes as efficient endonucleases and as selective metal biosensors, Chem. Eur. J. 8, 4588-4596.

4. Navani, N. K., and Li, Y. (2006) Nucleic acid aptamers and enzymes as sensors, Curr. Opin. Chem. Biol. 10, 272-281.

5. Silverman, S. K. (2010) DNA as a versatile chemical component for catalysis, encoding, and stereocontrol, Angew. Chem. Int. Ed. 49, 7180-7201.

6. Schlosser, K., and Li, Y. F. (2009) Biologically inspired synthetic enzymes made from DNA, Chem. Biol. 16, 311-322.

7. Silverman, S. K. (2009) Deoxyribozymes: Selection design and serendipity in the development of DNA catalysts, Acc. Chem. Res. 42, 1521-1531.

8. Breaker, R. R., and Joyce, G. F. (1994) A DNA enzyme that cleaves RNA, Chem. Biol. 1, 223-229.

9. Joyce, G. F. (2004) Directed evolution of nucleic acid enzymes, Ann. Rev. Biochem. 73, 791-836.

10. Liu, J., Cao, Z., and Lu, Y. (2009) Functional nucleic acid sensors, Chem. Rev. 109, $1948-1998$.

11. Zhang, X.-B., Kong, R.-M., and Lu, Y. (2011) Metal ion sensors based on DNAzymes and related DNA molecules, Annu. Rev. Anal. Chem. 4, 105-128. 
12. Torabi, S.-F., Wu, P., McGhee, C. E., Chen, L., Hwang, K., Zheng, N., Cheng, J., and Lu, Y. (2015) In vitro selection of a sodium-specific DNAzyme and its application in intracellular sensing, Proc. Natl. Acad. Sci. U.S.A. 112, 5903-5908.

13. Baum, D. A., and Silverman, S. K. (2008) Deoxyribozymes: Useful DNA catalysts in vitro and in vivo, Cell. Mol. Life Sci. 65, 2156-2174.

14. Lu, Y., and Liu, J. (2006) Functional DNA nanotechnology: Emerging applications of DNAzymes and aptamers, Curr. Opin. Biotechnol. 17, 580-588.

15. Lu, Y. (2006) Metalloprotein and metallo-DNA/RNAzyme design: Current approaches, success measures, and future challenges, Inorg. Chem. 45, 9930-9940.

16. Huang, P.-J. J., Lin, J., Cao, J., Vazin, M., and Liu, J. (2014) Ultrasensitive DNAzyme beacon for lanthanides and metal speciation, Anal. Chem. 86, 1816-1821.

17. Huang, P.-J. J., Vazin, M., Matuszek, Ż., and Liu, J. (2015) A new heavy lanthanidedependent DNAzyme displaying strong metal cooperativity and unrescuable phosphorothioate effect, Nucleic Acids Res. 43, 461-469.

18. Huang, P.-J. J., Vazin, M., and Liu, J. (2014) In vitro selection of a new lanthanidedependent DNAzyme for ratiometric sensing lanthanides, Anal. Chem. 86, 9993-9999.

19. Nishiyabu, R., Hashimoto, N., Cho, T., Watanabe, K., Yasunaga, T., Endo, A., Kaneko, K., Niidome, T., Murata, M., Adachi, C., Katayama, Y., Hashizume, M., and Kimizuka, N. (2009) Nanoparticles of adaptive supramolecular networks self-assembled from nucleotides and lanthanide ions, J. Am. Chem. Soc. 131, 2151-2158.

20. Wang, F., Liu, B., Huang, P.-J. J., and Liu, J. (2013) Rationally designed nucleobase and nucleotide coordinated nanoparticles for selective DNA adsorption and detection, Anal. Chem. 85, 12144-12151. 
21. Zhang, M., Le, H.-N., Jiang, X.-Q., Yin, B.-C., and Ye, B.-C. (2013) Time-resolved probes based on guanine/thymine-rich DNA-sensitized luminescence of terbium(III), Anal. Chem. 85, 11665-11674.

22. Kim, H.-K., Li, J., Nagraj, N., and Lu, Y. (2008) Probing metal binding in the 8-17 DNAzyme by $\mathrm{Tb}^{\mathrm{III}}$ luminescence spectroscopy, Chem. Eur. J 14, 8696-8703.

23. Feig, A. L., Panek, M., Horrocks, W. D., Jr, and Uhlenbeck, O. C. (1999) Probing the binding of $\mathrm{Tb}(\mathrm{III})$ and $\mathrm{Eu}(\mathrm{III})$ to the hammerhead ribozyme using luminescence spectroscopy, Chem. Biol. 6, 801-810.

24. Komiyama, M., Takeda, N., and Shigekawa, H. (1999) Hydrolysis of DNA and RNA by lanthanide ions: Mechanistic studies leading to new applications, Chem. Commun., 14431451.

25. Marciniec, T., Ciesiołka, J., Wrzesinski, J., and Krzyżosiak, W. J. (1989) Identification of the magnesium, europium and lead binding sites in E. Coli and lupine tRNA ${ }^{\text {phe }}$ by specific metal ion-induced cleavages, FEBS Lett. 243, 293-298.

26. Feig, A. L., Scott, W. G., and Uhlenbeck, O. C. (1998) Inhibition of the hammerhead ribozyme cleavage reaction by site-specific binding of $\mathrm{Tb}(\mathrm{III})$, Science $279,81-84$.

27. Dokukin, V., and Silverman, S. K. (2012) Lanthanide ions as required cofactors for DNA catalysts, Chem. Sci. 3, 1707-1714.

28. Geyer, C. R., and Sen, D. (1998) Lanthanide probes for a phosphodiester-cleaving, leaddependent, DNAzyme, J.Mol.Biol. 275, 483-489.

29. Huang, P.-J. J., and Liu, J. (2014) Sensing parts-per-trillion $\mathrm{Cd}^{2+}, \mathrm{Hg}^{2+}$, and $\mathrm{Pb}^{2+}$ collectively and individually using phosphorothioate DNAzymes, Anal. Chem. 86, 59996005. 
30. Sigel, R. K. O., and Sigel, H. (2010) A stability concept for metal ion coordination to single-stranded nucleic acids and affinities of individual sites, Acc. Chem. Res. 43, 974984.

31. Huang, P.-J. J., and Liu, J. (2015) Rational evolution of $\mathrm{Cd}^{2+}$-specific dnazymes with phosphorothioate modified cleavage junction and $\mathrm{Cd}^{2+}$ sensing, Nucleic Acids Res. 43, 6125-6133.

32. Wang, S., Karbstein, K., Peracchi, A., Beigelman, L., and Herschlag, D. (1999) Identification of the hammerhead ribozyme metal ion binding site responsible for rescue of the deleterious effect of a cleavage site phosphorothioate, Biochemistry 38, 1436314378.

33. Thaplyal, P., Ganguly, A., Golden, B. L., Hammes-Schiffer, S., and Bevilacqua, P. C. (2013) Thio effects and an unconventional metal ion rescue in the genomic hepatitis delta virus ribozyme, Biochemistry 52, 6499-6514.

34. Lin, W. T. D., Huang, P.-J. J., Pautler, R., and Liu, J. (2014) The group trend of lanthanides binding to DNA and DNAzymes with a complex but symmetric pattern, Chem. Commun. 50, 11859-11862.

35. Rordorf, B. F., and Kearns, D. R. (1976) Effect of europium(III) on the thermal denaturation and cleavage of transfer ribonucleic acids, Biopolymers 15, 1491-1504.

36. Frederiksen, J. K., and Piccirilli, J. A. (2009) Separation of RNA phosphorothioate oligonucleotides by HPLC, Methods Enzymol. 468, 289-309.

37. Nawrot, B., Widera, K., Sobczak, M., Wojcik, M., and Stec, W. J. (2008) Effect of R(p) and $\mathrm{S}(\mathrm{p})$ phosphorothioate substitution at the scissile site on the cleavage activity of deoxyribozyme 10-23, Curr. Org. Chem. 12, 1004-1009. 
38. Warnecke, J. M., Fuerste, J. P., Hardt, W.-D., Erdmann, V. A., and Hartmann, R. K. (1996) Ribonuclease $\mathrm{p}$ (RNase $\mathrm{p}$ ) RNA is converted to a $\mathrm{Cd}^{2+}$-ribozyme by a single Rpphosphorothioate modification in the precursor tRNA at the RNase P cleavage site, Proc. Natl. Acad. Sci. U.S.A. 93, 8924-8928.

39. Padgett, R. A., Podar, M., Boulanger, S. C., and Perlman, P. S. (1994) The stereochemical course of group II intron self-splicing, Science 266, 1685-1688.

40. Koizumi, M., and Ohtsuka, E. (1991) Effects of phosphorothioate and 2-amino groups in hammerhead ribozymes on cleavage rates and magnesium binding, Biochemistry 30, 5145-5150.

41. Ward, W. L., Plakos, K., and DeRose, V. J. (2014) Nucleic acid catalysis: Metals, nucleobases, and other cofactors, Chem. Rev. 114, 4318-4342.

42. Li, J., Zheng, W., Kwon, A. H., and Lu, Y. (2000) In vitro selection and characterization of a highly efficient Zn(II)-dependent RNA-cleaving deoxyribozyme, Nucleic Acids Res. $28,481-488$.

43. Burgess, J. (1978) Metal ions in solution, Ellis Horwood Ltd. , Chichester.

44. Brown, A. K., Li, J., Pavot, C. M. B., and Lu, Y. (2003) A lead-dependent DNAzyme with a two-step mechanism, Biochemistry 42, 7152-7161.

45. Morrison, J. F., and Cleland, W. W. (1980) A kinetic method for determining dissociation constants for metal complexes of adenosine 5'-triphosphate and adenosine 5'-diphosphate, Biochemistry 19, 3127-3131.

46. Knobloch, B., Nawrot, B., Okruszek, A., and Sigel, R. K. O. (2008) Discrimination in metal-ion binding to RNA dinucleotides with a non-bridging oxygen or sulfur in the phosphate diester link, Chem. Eur. J 14, 3100-3109. 
47. Gatto, B., Palumbo, M., and Sissi, C. (2009) Nucleic acid aptamers based on the Gquadruplex structure: Therapeutic and diagnostic potential, Curr. Med. Chem. 16, 12481265.

48. Peracchi, A., Bonaccio, M., and Clerici, M. (2005) A mutational analysis of the 8-17 deoxyribozyme core, J. Mol. Biol. 352, 783-794. 